\title{
Study on the Optimal Prestress Level of RC Beams Reinforced with SMA Bars
}

\author{
Zeying Yang, ${ }^{1}$ Zhengquan Cheng, ${ }^{1}$ Tianmin Wang, ${ }^{2}$ Yinglin Sun $\mathbb{D}^{1},{ }^{1}$ Chenghe Wang, \\ Jianbo Qu, ${ }^{3}$ Da Zhang, ${ }^{4}$ and Qiang $\mathrm{Li}^{4}$ \\ ${ }^{1}$ School of Civil Engineering, Shandong University, Jinan, Shandong 250061, China \\ ${ }^{2}$ Shandong Transportation Planning and Design Institute Group Co. Ltd, Jinan, Shandong 250031, China \\ ${ }^{3}$ Shandong Provincial Transportation Service Center, Jinan, Shandong 250002, China \\ ${ }^{4} J i y u a n$ Jijin Expressway Co. LTD, Jiyuan, Henan 454650, China
}

Correspondence should be addressed to Yinglin Sun; 1916878460@qq.com

Received 21 July 2021; Revised 6 October 2021; Accepted 22 November 2021; Published 22 December 2021

Academic Editor: Jiang $\mathrm{Hu}$

Copyright (C) 2021 Zeying Yang et al. This is an open access article distributed under the Creative Commons Attribution License, which permits unrestricted use, distribution, and reproduction in any medium, provided the original work is properly cited.

In order to study the optimal prestress level of RC (reinforced concrete) beams strengthened by SMA bars, the finite element software ABAQUS was used to numerically simulate the shear performance of RC beams strengthened by SMA bars with different prestress levels. By using the finite element software ABAQUS, the model of RC beams strengthened by SMA bars with different prestressing levels was established. The influence of SMA bars with different prestressing levels on the shear capacity of RC beams was analyzed from the aspects of stress, strain, load, deflection, and maximum bearing capacity, and the failure types and failure processes of RC beams strengthened with different prestressing levels were obtained. Comparing the numerical simulation results with the experimental results, it is found that the error between the finite element simulation results and the experimental results is less than $10 \%$.

\section{Introduction}

In the finite element simulation, various materials in buildings use the material constitutive model to simulate their own properties, such as the stress-strain relationship. The constitutive models of concrete materials in the finite element software ABAQUS include the plastic damage model, smeared cracking model, and brittle cracking model of concrete. It can not only impose arbitrary reciprocating load on the concrete structure but also simulate various behaviors of the concrete structure under arbitrary reciprocating load, such as concrete crack development, concrete damage, and concrete stiffness recovery. At the same time, it also considers the degradation of elastic stiffness caused by tension and compression plastic strain and the stiffness recovery under cyclic loading, which has good convergence.

Based on the concrete constitutive model in ABAQUS, this paper debugs the materials in actual engineering on the basis of the existing constitutive model, which obtains the constitutive model that meets the requirements of numerical analysis. Through comparison and verification, the plastic constitutive damage model was selected to simulate the stress-strain relationship and load-deflection relationship of the test components.

\section{Finite Element Model of RC Beam}

2.1. Test Scheme. In this experiment, 5 reinforced concrete beams were designed. One beam (RCL1) was used as the benchmark beam without reinforcement, the other 3 beams (RCL2, RCL3, and RCL4) were reinforced with SMA bars of different prestress levels, and the other was used as the spare beam. The pseudostatic loading test was carried out on 5 beams. The size of the test beam is $100 \times 200 \times 1300 \mathrm{~mm}$. Two tensile rebars are arranged in the tensile area of the test beam. The longitudinal reinforcement ratio is $1.92 \%$, which is less than the limit reinforcement ratio of $2.62 \%$. The shear span ratio is 2.5. The concrete strength is $\mathrm{C} 30$, and the 
thickness of the protective layer is $20 \mathrm{~mm}$. The spacing of bars is $150 \mathrm{~mm}$. The longitudinal reinforcement is an HRB400 rebar with a diameter of $12 \mathrm{~mm}$. The auxiliary steel bar is an HPB300 rebar with a diameter of $10 \mathrm{~mm}$. The stirrup is an HPB300 hot rolled plain rebar with a diameter of $6 \mathrm{~mm}$. There are 8 reinforcement strain gages. The diameter of SMA bars used to reinforce concrete beams is $2.2 \mathrm{~mm}$, and the sectional area is $3.8 \mathrm{~mm}^{2}$. The shear span ratio and the spacing of SMA bars outside the concrete of each test beam were the same. The experimental loading device is shown in Figure 1.

2.2. Element Selection. In the finite element simulation analysis, whether a more accurate convergence solution can be obtained depends on the error of the model used. A good finite element model requires not only high mesh quality but also an appropriate element control structure type. ABAQUS contains a large number of element libraries, which can basically simulate finite element models of arbitrary geometric shapes in actual engineering. The most commonly used elements are the solid element, shell element, and beam element. In this paper, a C3D8R three-dimensional entity element is adopted.

2.3. Material Model. In the finite element analysis of structures, it is very important to determine the properties of materials. Therefore, at the beginning of the preparation stage of the test, it is necessary to test the material first to provide more accurate data support for the definition of material properties in the finite element.

The stress and strain obtained in the reinforcement material property test are transformed into real stress and strain. Then, the real strain is transformed into two parts: elastic strain and plastic strain. Based on the existing constitutive theory, the damage plasticity constitutive model of concrete is established by using the yield criterion. The constitutive model suitable for the finite element simulation of the project is obtained through the corresponding debugging and calculation of the materials used in the actual project.

2.4. Boundary Conditions and Meshing. For general reinforced concrete structures, embedded boundary conditions are usually used in the finite element model analysis, which means the reinforcement is directly embedded into the concrete, ignoring the bonding effect between the reinforcement and the concrete. For reinforced beams, tie boundary conditions are used between concrete and SMA bars. The steel bar and shape memory alloy parts are shown in Figures 2 and 3. An arc length method is adopted to solve the problem. In order to achieve better analytical convergence of the model, the initial increment is set to a small value. The calculation accuracy and convergence effect of the finite element model are guaranteed by a reasonable meshing method. The mesh size selected for the whole model is 0.02 . Model establishment and mesh partition are shown in Figure 4.

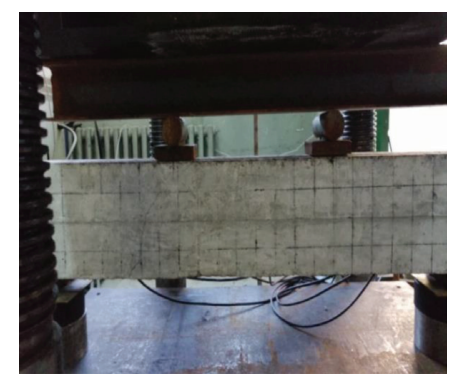

Figure 1: Test loading device diagram.

\section{Comparison and Analysis of Simulation Results and Experimental Results}

The results of four groups of concrete beams were obtained by ABAQUS analysis, including the plastic strain nephogram of concrete beams, the stress nephogram of reinforcing bars, and the stress nephogram of SMA bars. The loaddeflection curve data of the beam, the failure mode of the beam, and the ultimate load that the beam can bear obtained by the finite element software ABAQUS are compared with the test data, which shows the results of the two that are very consistent.

3.1. Analysis of Beam Plastic Strain Nephogram. Figure 5 presents four groups of reinforced concrete beams with plastic stress and strain strength nephogram obtained from finite element numerical simulation analysis. It can be seen from the figure that the maximum principal tensile stress of the beam is concentrated at the bottom of the beam and extends along the oblique section direction of the beam from the middle two sides of the beam. The maximum tensile stress in the compression zone of the beam is negative, which is usually called the maximum principal compressive stress. When the maximum principal tensile stress of concrete is greater than the tensile strength, the beam will crack, and the direction of the crack extension is perpendicular to the direction of the maximum principal tensile stress, which is consistent with the test results.

3.2. Failure Mode Analysis. Failure modes are shown in Figure 6. Figures 7 10 show the results obtained from the analysis of the finite element software of ABAQUS, including the stress nephogram of reinforcement and the plastic strain nephogram of the beam, through which the failure modes of the beam are analyzed.

3.2.1. Nephogram of Concrete Plastic Strain. By analyzing the plastic strain nephogram of concrete in each specimen, it can be seen that there are two kinds of failure modes. Among them, RCL1, RCL2, and RCL3 have shear compression failure, whose failure characteristics are as follows: after the appearance of bending-shear oblique crack, the load can still maintain a relatively large increase. With the increase of load, other bending-shear inclined cracks will appear successively, and one of them will develop into a major inclined 


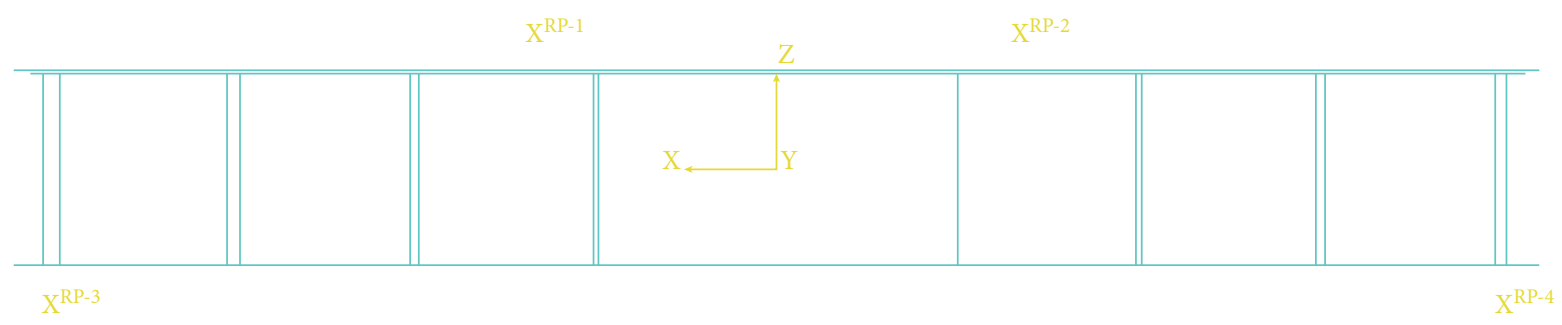

Figure 2: Reinforcement components.
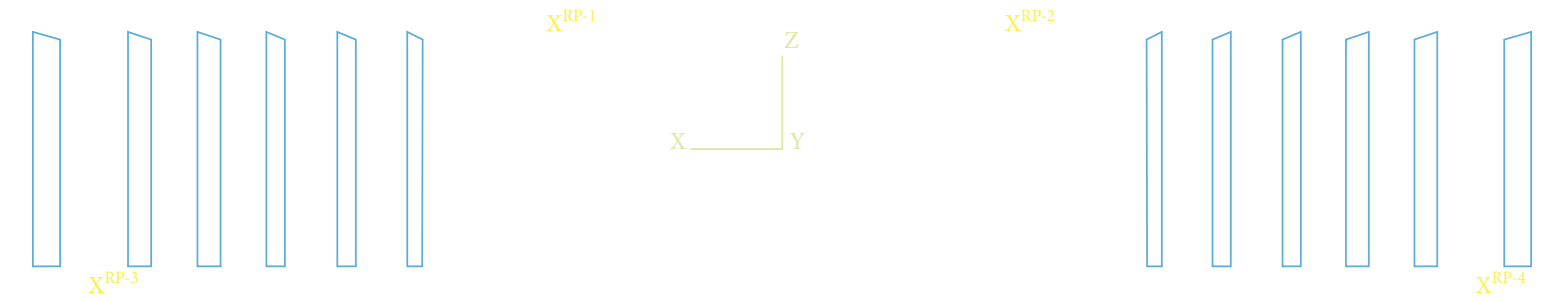

Figure 3: Shape memory alloy components.

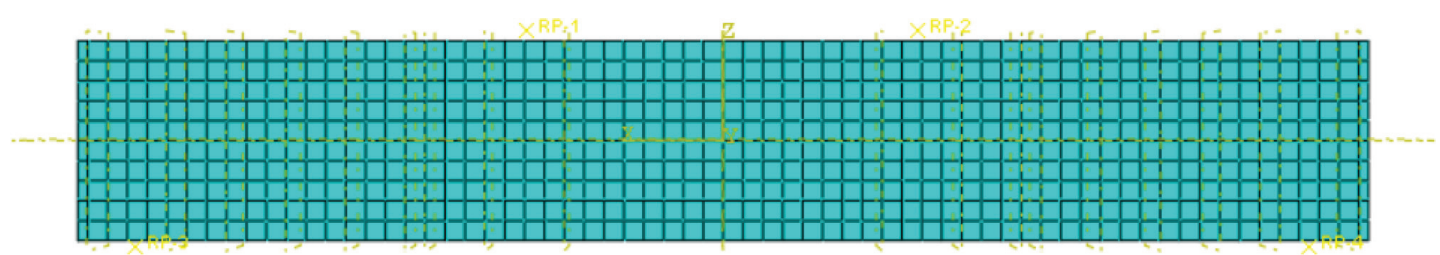

FIGURE 4: Mesh division of finite element model.

crack, which is called the critical diagonal crack. As the load continues to increase, it is concentrated at the upper end of the critical diagonal crack near the point of application. When the beam reaches the ultimate bearing capacity, the shear section of the inclined section is shown as a plastic zone, which expands from the lower support to the upper end of the pad where the load is applied so that the concrete is destroyed. When the prestress level of SMA bars is increased, the plastic strain value and the zone of concrete in the shear zone will decrease. On the contrary, the plastic strain value and the zone of the concrete in the compression zone increase with the increase of the prestress level of SMA bars, which is consistent with the experimental data. When the prestress level of $14 \%$ is applied to the strengthened beams in RCL4, it can be seen that bending failure occurs to the beams at this time, and the maximum plastic strain is concentrated at the flexural section of the beams. In the beginning, the plastic strain area extends from the lower end of the bearing to the place where the load gasket is applied. Because the prestress applied by the beams of the Group 4 of reinforced beams is larger, the SMA reinforcement will produce a large prestress, which increases the constraint on the beam, inhibits the extension of concrete cracks in the shear zone, strengthens the shear zone, and makes the bending zone become a weak zone. With the increase of load, the plastic strain value and the plastic strain area of concrete in the shear zone are increasing. The concrete in the compression zone is crushed, and the bending failure of RCL4 finally occurs, which is consistent with the current experimental results.

3.2.2. Nephogram of Steel Bar Stress. From Figures 7 and 10 beam stress nephogram, the maximum stress intensity values of RCL1, RCL2, and RCL3 beams are located in the shear zone of the beam, that is, the pressure path stirrup where the bearing expands to the load cushion block. The increase of SMA reinforced prestress makes the stirrup yield load increase. Because the longitudinally compressed steel bar is not the main force component, it acts as the erecting steel bar, so it yields earlier. When the external load applied reaches the maximum load that the beam can bear, the stirrup at this time reaches the yield strength, and the crack runs through the entire beam interface in the shear zone, causing damage to the component. However, for the RCL4 specimen, the maximum stress value of the steel bar in the beam appears in the middle of the longitudinal tensile steel bar. When the applied load reaches the ultimate load that the beam can bear, although the longitudinal tensile steel bar of the beam reaches the yield, the stirrup at this time has not reached the yield strength, which results in the bending failure of RCL4.

The plastic strain diagram of concrete and Mises stress nephograms of steel bars of each specimen were obtained by 

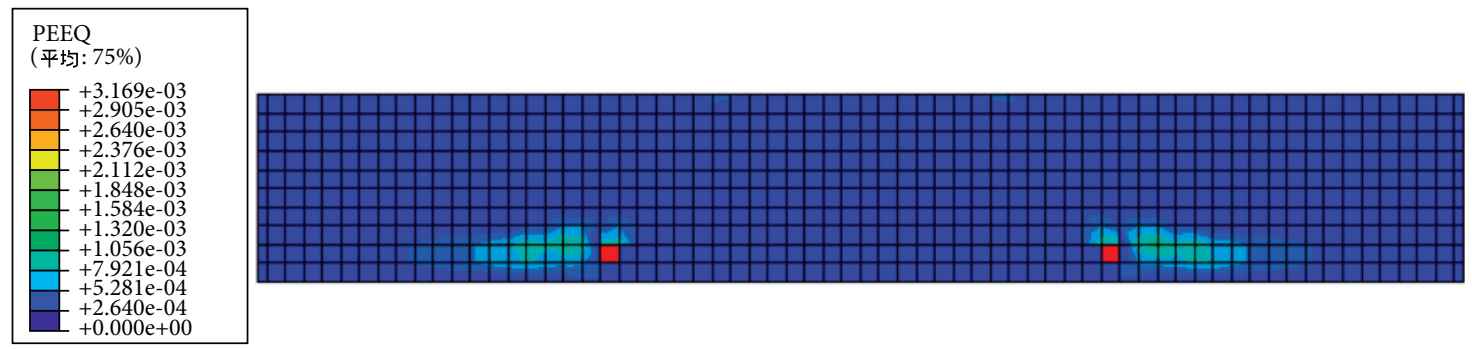

(a)
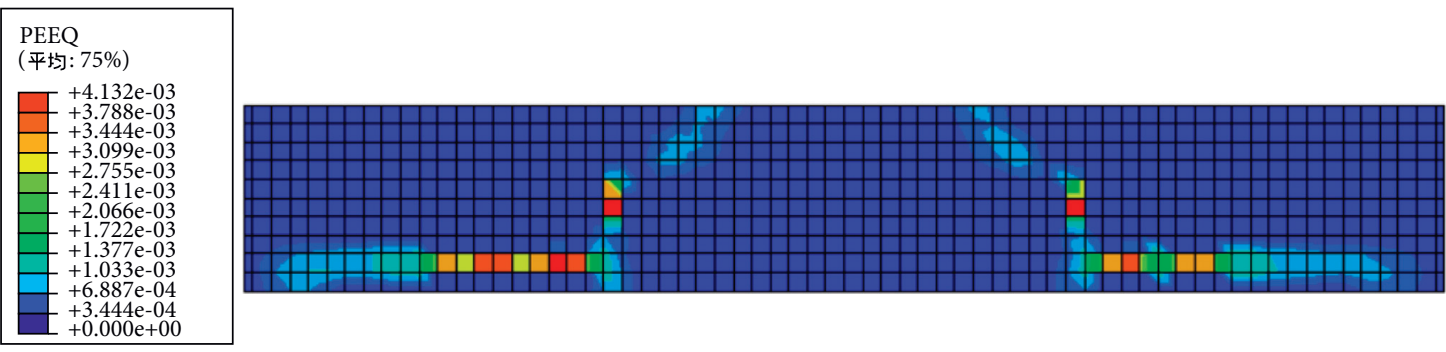

(b)
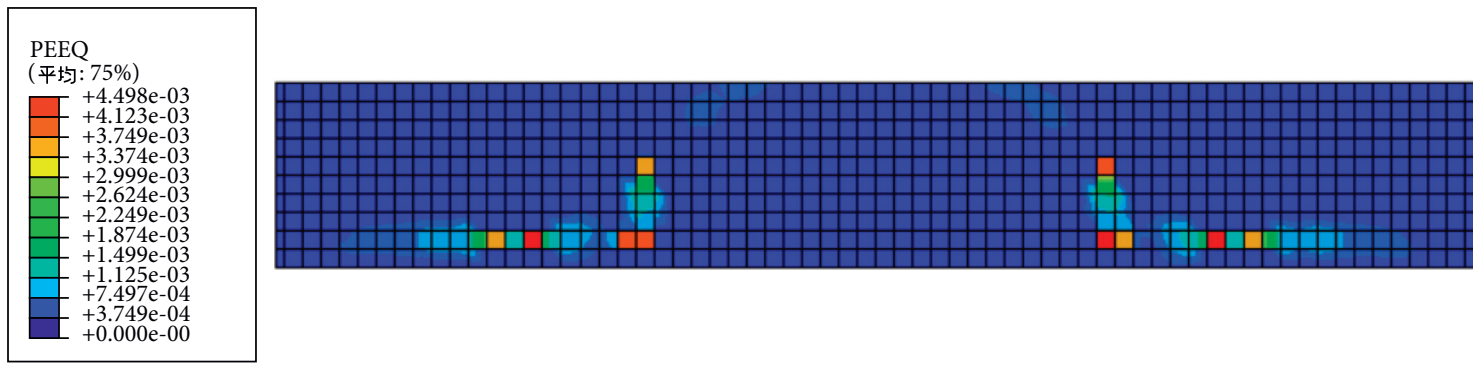

(c)
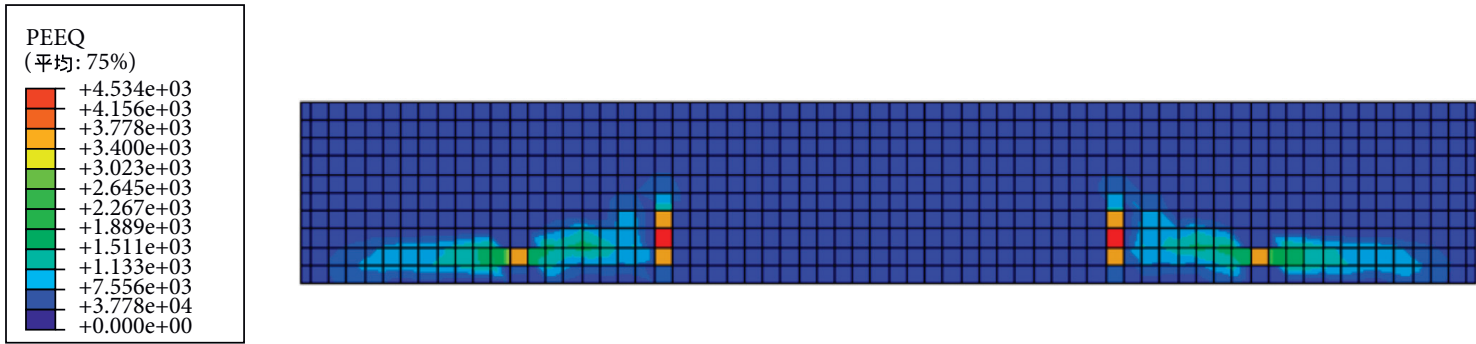

(d)

FIgURE 5: Plastic strain nephogram of concrete. (a) Plastic strain diagram of RCL1 concrete. (b) Plastic strain diagram of RCL2 concrete. (c) Plastic strain diagram of RCL3 concrete. (d) Plastic strain diagram of RCL4 concrete.

ABAQUS finite element analysis software. The results show that the failure position of the beam simulated by ABAQUS is basically the same as the failure position of the test beam, which indicates that ABAQUS can well simulate the whole process of the beam failure.

3.3. Stress Nephogram Analysis of SMA Bars. Figures 11(a)-11(c) show the stress cloud images of SMA bars with prestressing levels of $6 \%, 10 \%$, and $14 \%$, respectively. It can be seen that the stress of SMA bars increases gradually in the process of load, and the stress near the bottom support of the reinforced concrete beam is the largest, which gradually spreads to both ends of the beam. The SMA bars with the prestress level of $14 \%$ produce the greatest stress, which is equivalent to creating a hoop for the reinforced concrete beam.

3.4. Load-Deflection Curve Analysis. The relationship between the simulated load of RCL1, RCL2, RCL3, and RCL4 and the midspan deflection curve was obtained through finite element software analysis. From the simulation results, the load deflection curves of each specimen can be divided into three stages.

3.4.1. Elastic Stage. With the increase of the load applied to the beam, the midspan deflection of the beam has a linear relationship with the load. The load-displacement curves of 


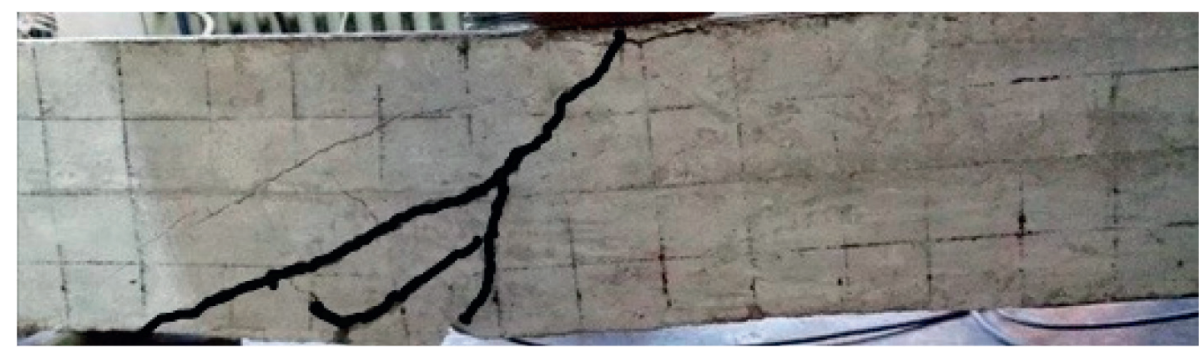

(a)

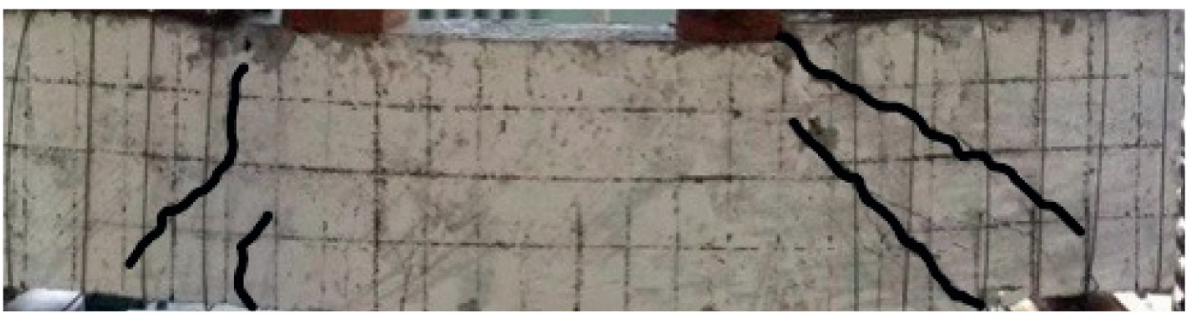

(b)

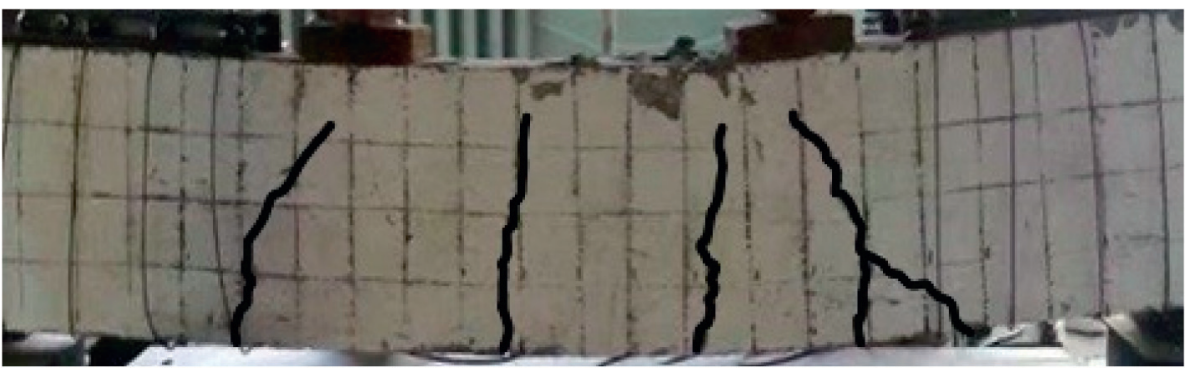

(c)

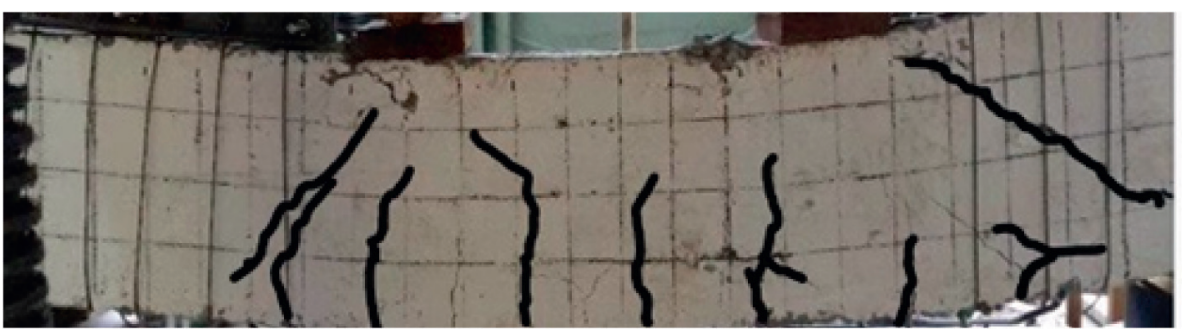

(d)

Figure 6: Diagram of shear failure of test beam. (a) Overall diagram of RCL1 limit damage. (b) Overall diagram of RCL2 limit damage. (c) Overall diagram of RCL3 limit damage. (d) Overall diagram of RCL4 limit damage.

the four groups of specimens in the elastic stage are basically coincident, which indicates that the cracks in the shear zone of the beams strengthened with SMA bars do not appear at this stage. There is no significant difference in the ductility and strength between the treated SMA bars and the untreated SMA bars.

3.4.2. Elastoplastic Stage. With the increase of the applied load, the midspan deflection of the beam no longer has a linear relationship with the load, and the concrete in the shear area appears the oblique plastic zone along with the support to the cushion area, which indicates that the steel wire rope bears the part of the shear force, has a constraint effect on the beam body, and inhibits the development of oblique cracks. The maximum shear capacity of SMA reinforced beams is higher than that of unreinforced beams.

3.4.3. Plastic Failure Stage. The plastic zone of concrete in the compression zone of the first three groups of specimens extends to the whole beam height section, but the plastic zone of the fourth group of members is at the midspan bending of the beam. With the decrease of the load-deflection curve, the deflection of the midspan beam increases rapidly with the increase of the applied load. The reduction speed of the shear bearing capacity of the first group is significantly higher than that of the latter three groups. In the finite element simulation analysis stage, the SMA bars in the strengthened beam members are all intact. It can also be seen 

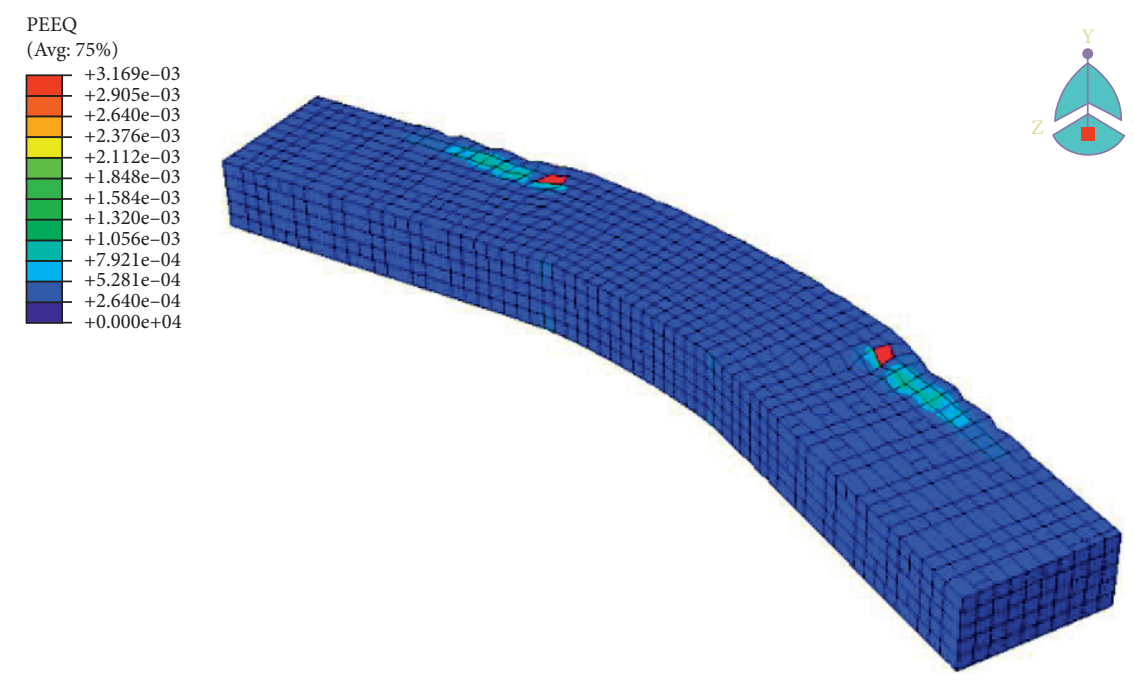

(a)
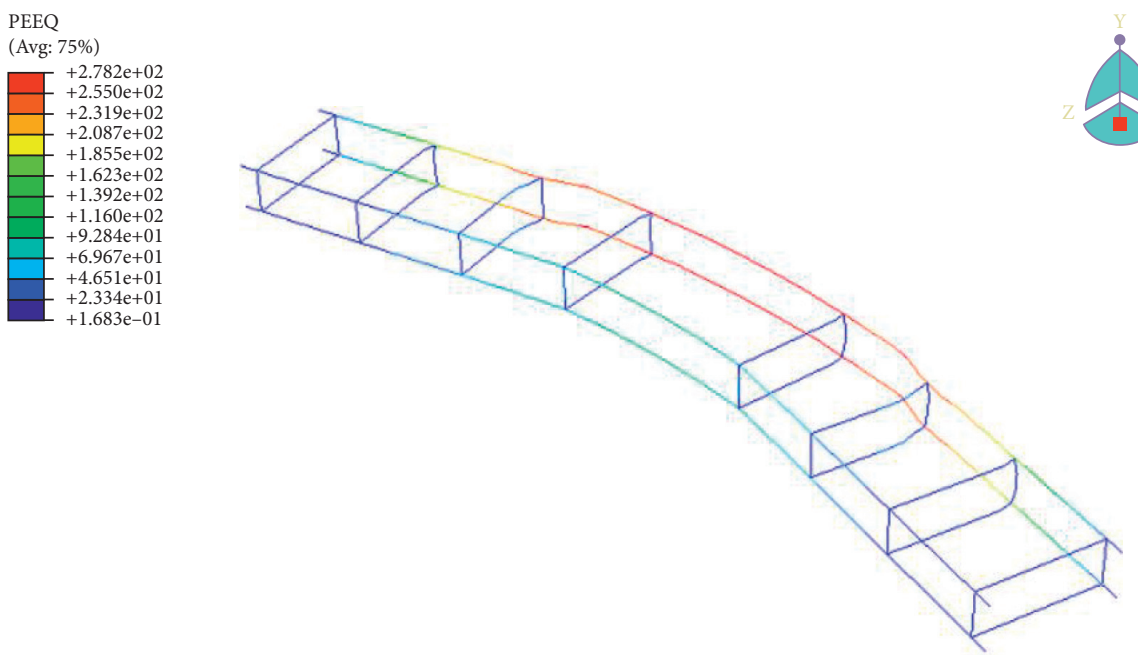

(b)

Figure 7: Failure mode of RCL1. (a) Plastic strain nephogram of RCL1 concrete. (b) Mises stress nephogram of RCL1 bar.

from the figure that there is a long horizontal straight segment in the load-deflection curve. The results obtained by simulation are in good agreement with those obtained by the experiment. From the simulation results, Table 1 shows the results of reinforcing beams with SMA bars. It can be seen that the strength and ductility of beams have been improved.

The finite element simulation results are compared with the experimental results, as shown in Figure 12. The ultimate load value of the beam obtained by ABAQUS finite element software is very close to that obtained by the experiment. The gap between the two methods is within $10 \%$. Due to the elastic-plastic constitutive relation cannot reach the given yield condition, there is a certain error between the finite element results and the experimental results, but these errors are within $10 \%$, which belongs to the acceptable range, indicating that it can be applied to the comparative analysis of the shear performance of RC beams strengthened with SMA bars.
3.5. Comparison of Relationship between the Maximum Bearing Capacity and the Level of Prestress. Various parameters used in the ABAQUS finite element model are the same as those used in the test, such as reinforcement ratio of SMA bars and spacing of reinforcement hoop. It can be seen from Figure 13 that the maximum shear capacity of the first three groups of beams increases with the increase of prestressing of SMA bars. For the fourth group of strengthened beams, when the prestress of SMA bars is $14 \%$, the bending failure occurs, and the ultimate bearing capacity of the beam is less than that of the third group. The main reason is that the large prestress increases the binding effect on the beam and reduces the crack extension of the beam in the shear zone. The corresponding strengthening of the shear zone makes the compression zone become a weak zone, thereby changing the failure mode of the beam. Therefore, the prestress level generated by setting SMA bars should not be too 


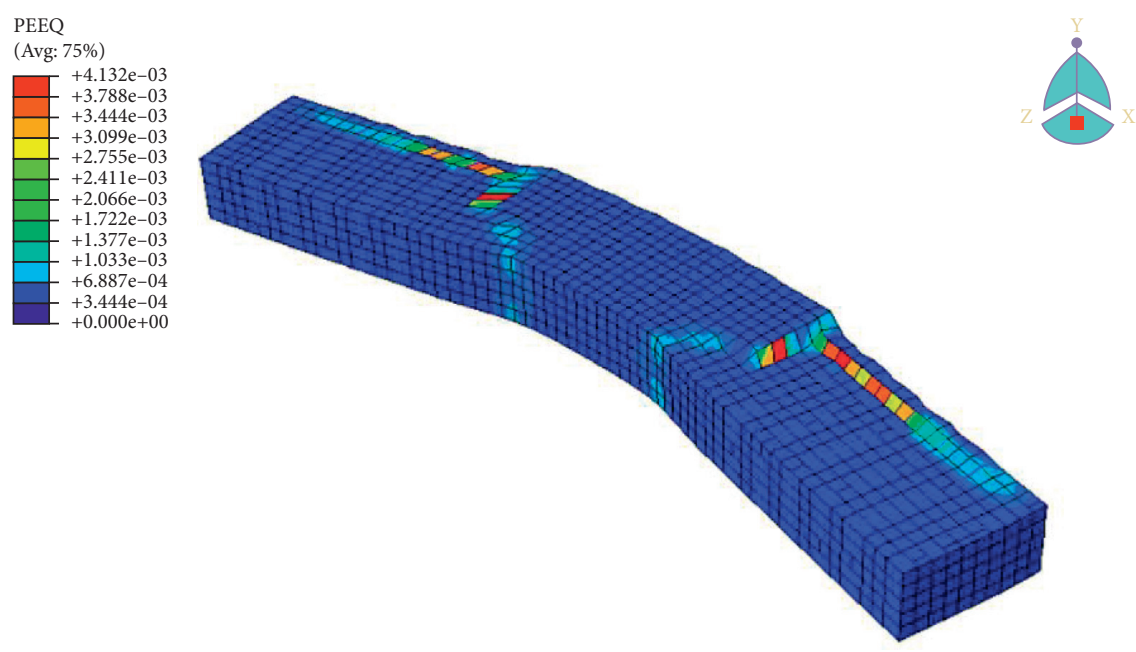

(a)
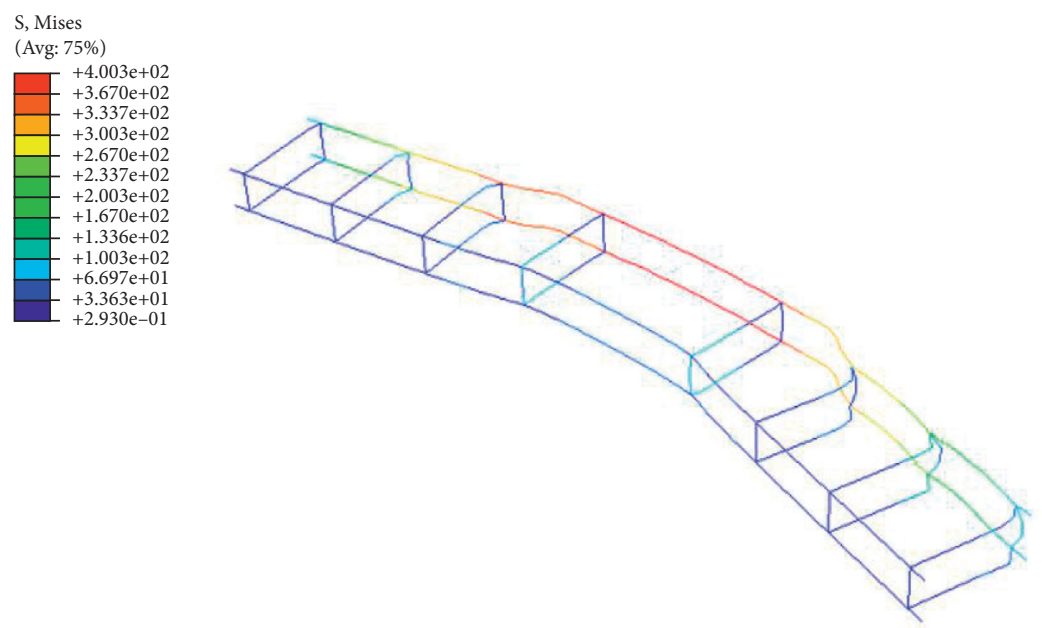

(b)

FIgURE 8: Failure mode of RCL2. (a) Plastic strain nephogram of RCL2 concrete. (b) Mises stress nephogram of RCL2 bar.

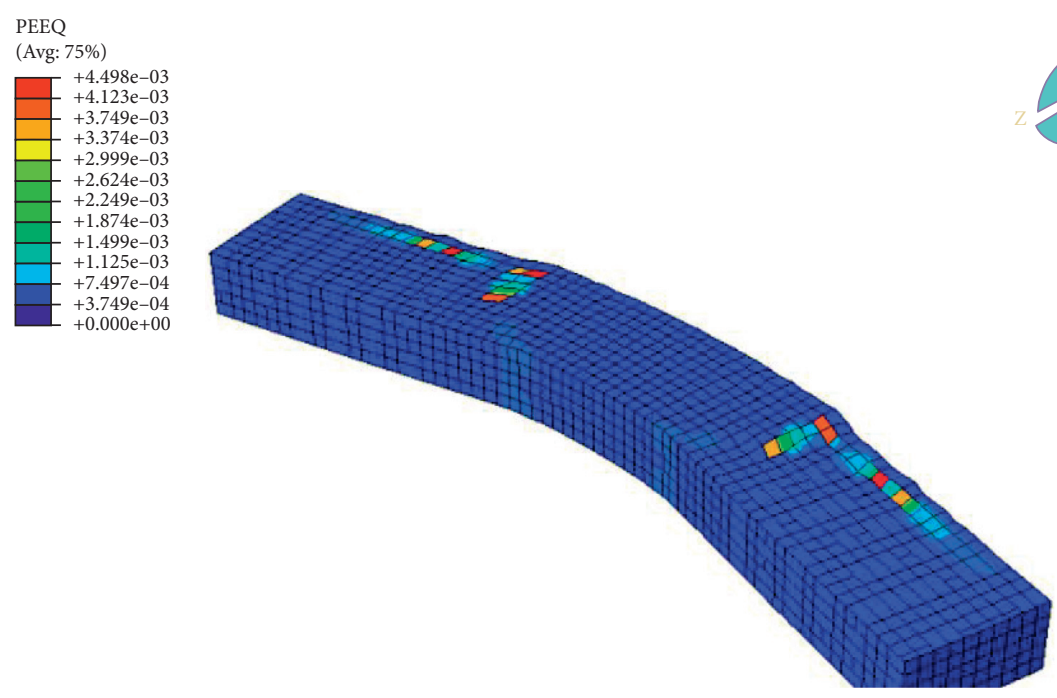

(a)

Figure 9: Continued. 

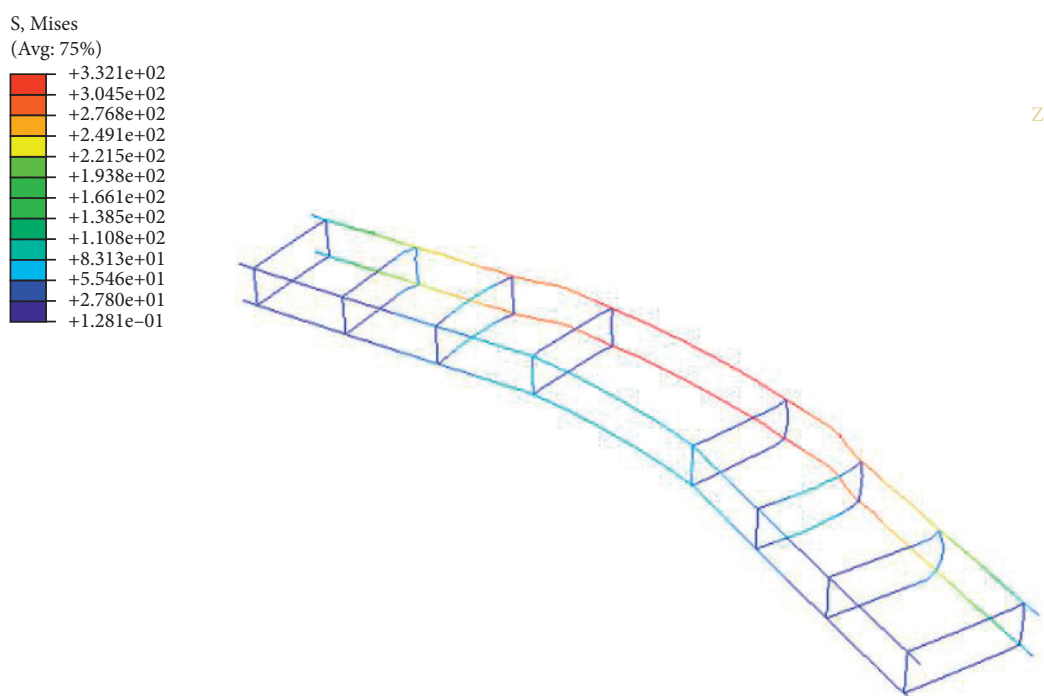

(b)

FIgURE 9: Failure mode of RCL3. (a) Plastic strain nephogram of RCL3 concrete. (b) Mises stress nephogram of RCL3 bar.
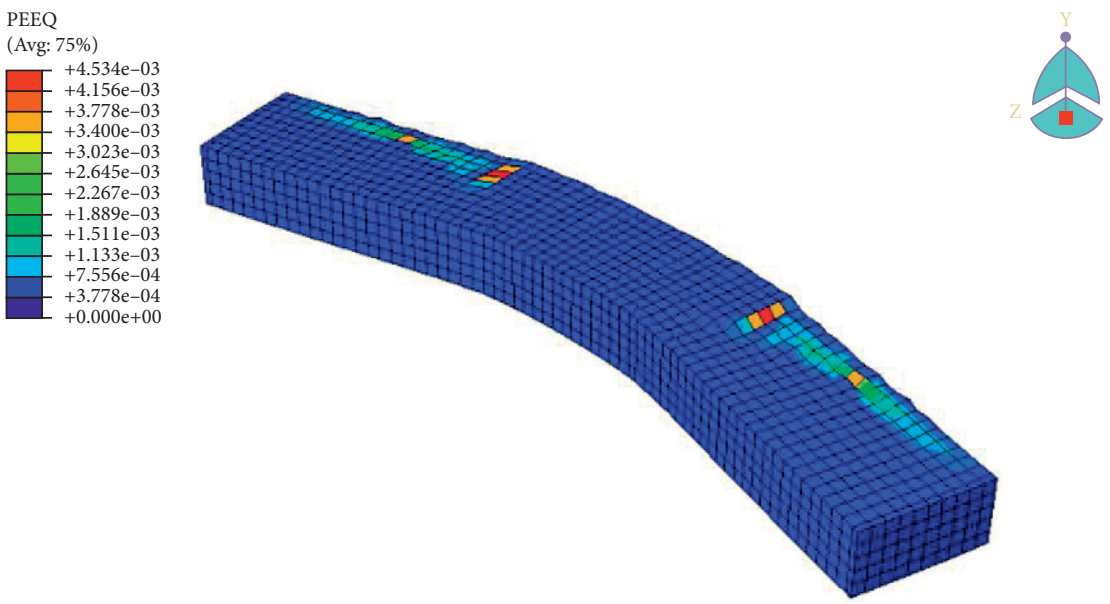

(a)
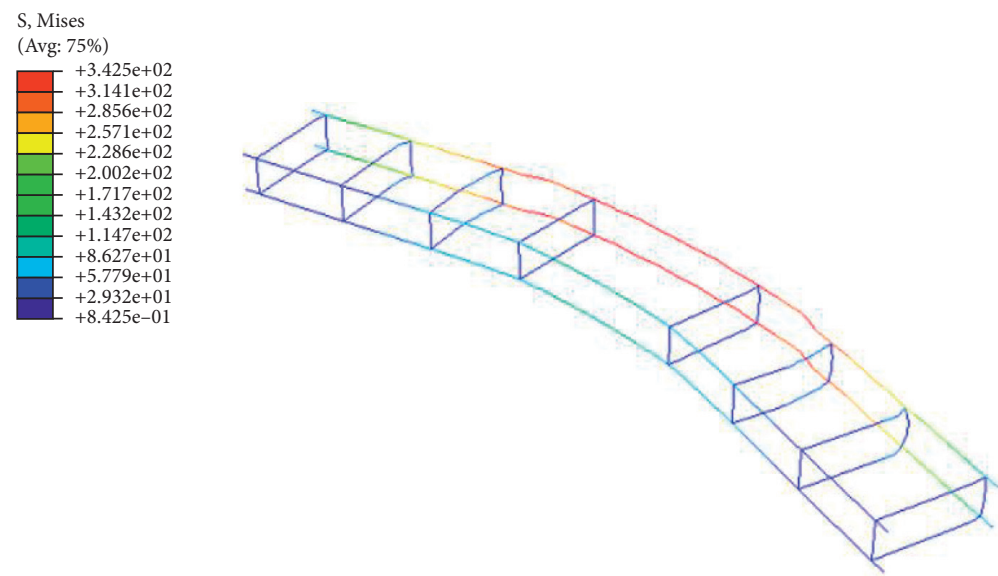

(b)

Figure 10: Failure mode of RCl4. (a) Plastic strain nephogram of RCL4 concrete. (b) Mises stress nephogram of RCL4 bar. 

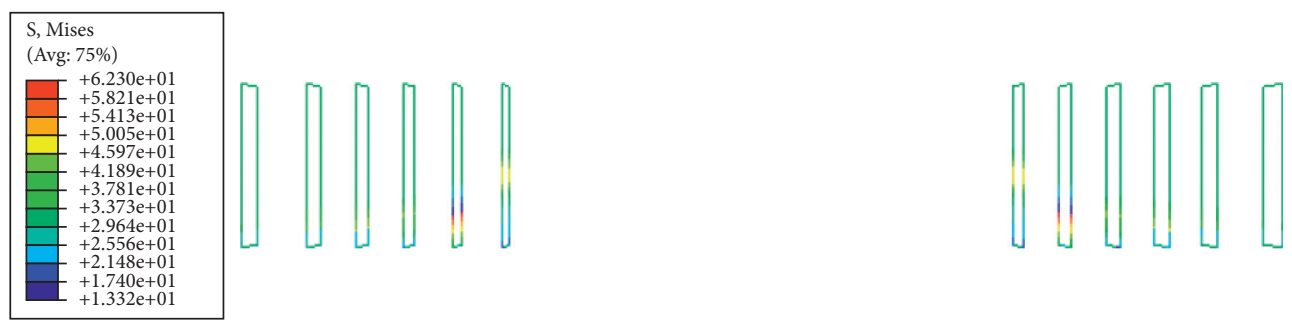

(a)

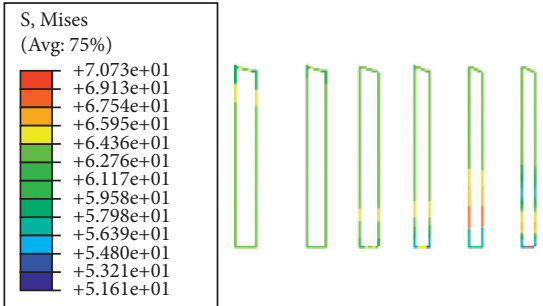

(b)

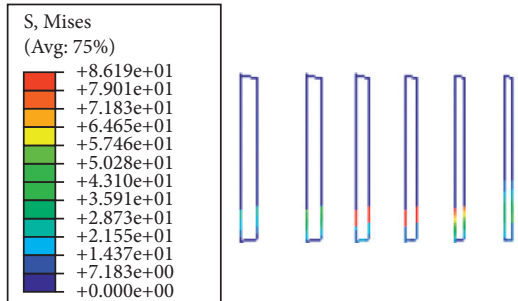

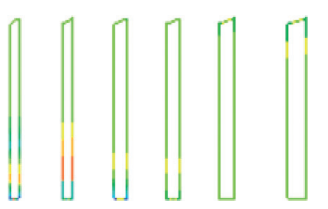

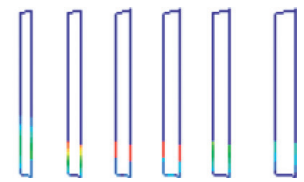

(c)

FIGURE 11: Simulated stress cloud of SMA bars. (a) RCL2 simulated stress nephogram of SMA bars. (b) RCL3 simulated stress nephogram of SMA bars. (c) RCL4 simulated stress nephogram of SMA bars.

TABLE 1: Simulation results of the main feature points of load deflection.

\begin{tabular}{lcccc}
\hline $\begin{array}{l}\text { Test specimen } \\
\text { number }\end{array}$ & $\begin{array}{c}\text { Prestress } \\
\text { level (\%) }\end{array}$ & $\begin{array}{c}\text { Ultimate } \\
\text { load }(\mathrm{kN})\end{array}$ & $\begin{array}{c}\text { Percentage increase in the } \\
\text { ultimate load of reinforced } \\
\text { specimens (\%) }\end{array}$ & Midspan deflection corresponding to ultimate load (mm) \\
\hline RCL1 & - & 79 & - & 13.04 \\
RCL2 & 6 & 83 & 5.06 & 14.89 \\
RCL3 & 10 & 89 & 12.66 & 20.79. \\
RCL4 & 14 & 86 & 8.86 & 15.69 \\
\hline
\end{tabular}
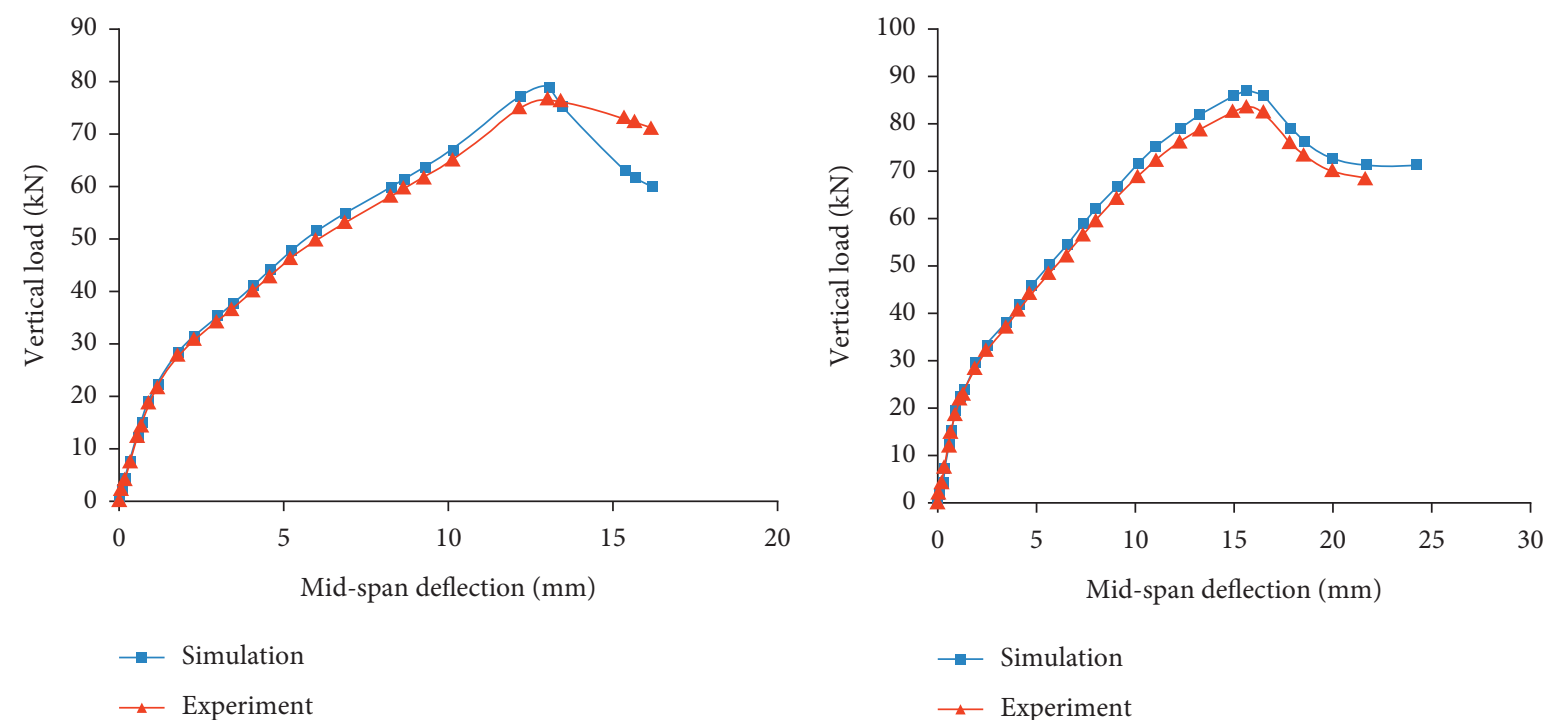

(a)

(b)

Figure 12: Continued. 


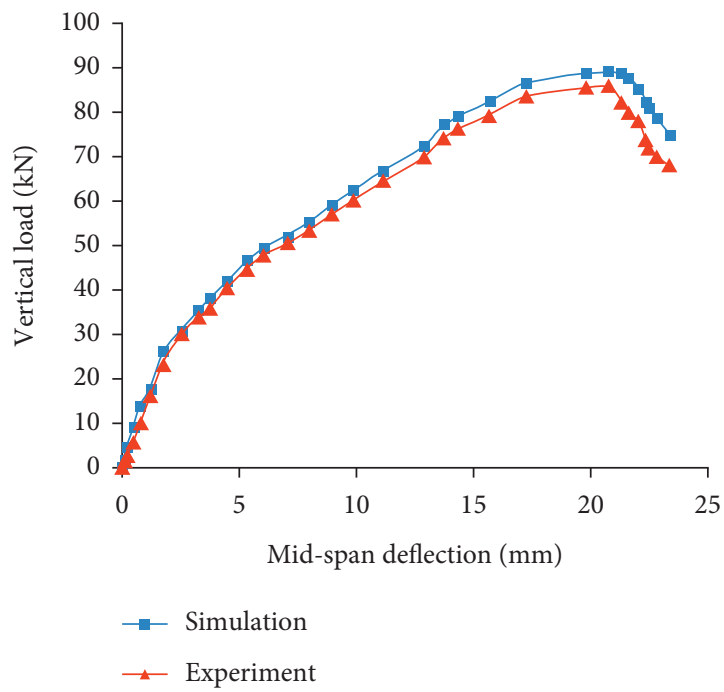

(c)

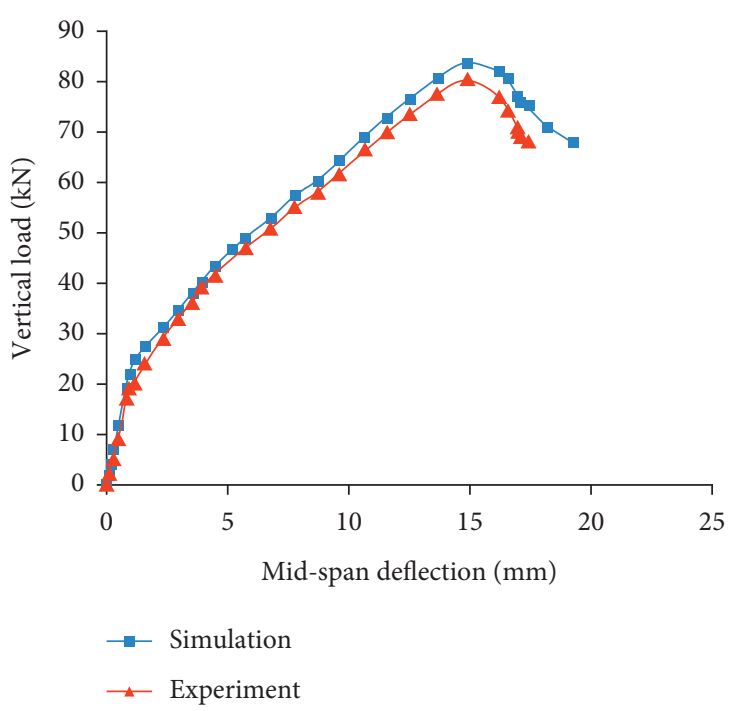

(d)

Figure 12: Comparison of deflection curves of simulated and tested loads. (a) Comparison of RCL1 simulation and test load deflection curves. (b) Comparison of deflection curves of simulated and tested RCL2 loads. (c) Comparison of RCL3 simulation and test load deflection curves. (d) Comparison of deflection curves of simulated and tested loads in RCL4.

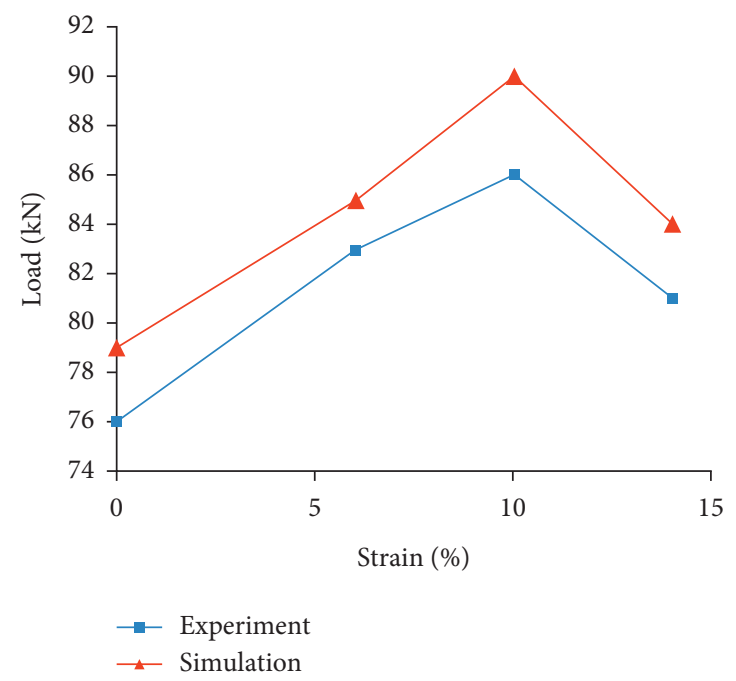

FIGURE 13: Comparison diagram of relationship between prestress level and maximum bearing capacity.

high. In addition, for the same prestress produced by the same prestress level, the ultimate load value of the beam obtained by simulation is greater than that of the test data.

\section{Conclusion}

By comparing the results of finite element numerical simulation with the experimental results, the conclusions are as follows:

(1) Both finite element analysis and laboratory tests show that shear failure occurs in the first three groups of beams, and bending failure occurs in the fourth group of beams.
(2) The finite element simulation and test of the proceeds of the load-deflection curves show that the strength and ductility of beams strengthened with SMA bars are greatly improved. The beam deflection of the curve can be divided into three stages. The first stage is the elastic stage, the main character is the linear relation between deflection and load, and deflection increases linearly with the load. The second stage is the elastic-plastic stage, which is mainly characterized by a plastic zone that appears in this part of the region extending from the shear zone of the beam to the loading place. The increase rate of the applied load is less than that of mid-span deflection, so the load-deflection curve is no longer linear. The third stage is the plastic stage. The plastic zone of the 
fourth group of test beams is mainly concentrated in the middle of the span, and the load-deflection curve decreases. The deflection of the midspan beam increases rapidly with the increase of load.

(3) The numerical simulation results are significantly higher than the experimental results for the ultimate bearing capacity of the strengthened beams. The reasons for the difference between the test results and the numerical simulation results are that the contact between the beam and the bearing is not close enough, the contact between the distribution beam and the beam body is not close enough, and the loading method is different. But the error is less than $10 \%$, which meets the value specified in the code. [1-10].

\section{Data Availability}

The data that support the findings of this study are available from the corresponding author upon reasonable request.

\section{Conflicts of Interest}

The authors declare that they have no conflicts of interest. Previous publications.

1. Zeying Yang, Yongye Qu, Jianbo Qu, Yalei Zhang, Wenchao Qi, Xinnan Xie. Research on Static Characteristics of Steel-Concrete Composite Beam Cable-Stayed Bridge during Construction. IOP Conference Series: Materials Science and Engineering.

2. Zeying YangYalei Zhang, Yaping Wang, Ning Wang, Haina Cui. Conventional Bridge Damage Identification Based on BP Neural Network. IOP Conference Series: Materials Science and Engineering.

3. Zeying YANG, Yangyudong Liu, Minghao Sun, Yongye Qu, Xinnan Xie, Yalei Zhang. Parametric analysis on mechanical performance of prestressed CFRP reinforced concrete bridge deck. Materials Science and Engineering. 397(2018), p 63-67.

4. Zeying YANG, Yongye Qu, Yangyudong Liu, Minghao Sun, Yalei Zhang, Xinnan Xie. Study on construction control technology for tower and beam synchronous construction of cable-stayed bridge. Materials Science and Engineering. 397(2018), p 68-75.

5. Yuhui Shan, Geng Liu, Qingwei Zhao, Zeying Yang, Yudong LiuYang. Paramatric Analysis of Stress Increment of Prestressed CFRP Reinforced Concrete Bridge Deck. 2018 International Conference on Chemical Engineering and Environmental ne Sustainability. p 68-75.

6. Zeying Yang, Yangyudong Liu, Minghao Sun, Yongye $\mathrm{Qu}$, Wenchao Qi. Experimental Research on Prestressed Carbon Fiber Reinforced Plastic Reinforced Concrete Decks. Journal of Highway Transportation Research and Development (English edition). 2018.12.

7. Zeying YANG, Minghao Sun, Yangyudong Liu, Yongye Qu, Yalei Zhang, Xinnan Xie. Stability analysis of synchronous construction of towers and beams of cablestayed bridge. Materials Science and Engineering. 397(2018), p 55-62.
8. Ze-Ying YANG, Ting-Ting TAN, Yang-Yudong LIU, Ming-Hao SUN. Replacement of Health Monitoring System and Health Evaluation for Jinan Yellow River Cable-stayed Bridge. Advances in Engineering Research (AER), volume 105(2016) p155-161.

9. Zeying YANG, Tingting YUAN, Jing LIU, Xinghua XI, Pan Gao. Experimental Study on the Mechanical Property of SMA Externally Prestressed Concrete Box Beam. Applied Mechanics and Materials Vols. 778 (2015) p50-54.

10. YANG Zeying, LIU Jing, QU Jianbo, ZHOU Xiangshan, LI Lixin. Temperature Field of PC Box Girder Bridge Based on GPRS Temperature Collection System. Wuhai University Journal of natural Sciences, 2015, v(20-3).

11. Zeying YANG, Jiayou LIU, Yidong ZHANG, Qianbo QU. Flexural Behavior Finite Element analysis of CFRP Reinforced Concrete Bridge Deck with Corrosion and Salt Resistance. v1004-1005, p 1474-1477, 2014, Advanced Materials and Technologies.

12. Zeying YANG, Yidong ZHANG, Huaming SUN, Qihiu SUN, Jiayou LIU. Experimental Study on Flexural Behavior of CFRP Bar Reinforced Concrete Bridge Deck with Corrosion and Salt Resistance. v 1004-1005, p 1450-1454, 2014, Advanced Materials and Technologies.

\section{Acknowledgments}

This work was supported by the Shandong Transportation Science and Technology Program (2011A21 and 2021B85).

\section{References}

[1] C. L. Cui, "Test on shear performance of RC concrete girder bridge strengthened by prestressed steel wire rope," Highway Traffic Science and Technology (Application Technology Edition), vol. 10, 2018.

[2] T. L. Yu, H. S. Li, and W. Huang, "Sears performance of reinforced concrete beams strengthened by prestressed steel wire rope," Journal of Jilin University (Engineering and Technology Edition), vol. 9, 2017.

[3] S. D. Xue, G. L. Shi, and P. Zhuang, "Experimental study on the performance of SMA reinforcement composite friction damper," Earthquake Engineering and Engineering Vibration, vol. 27, no. 2, p. 145, 2007.

[4] Z. Deng, Q. Li, and H. Sun, "Behavior of concrete beam with embedded shape memory alloy wires," Engineering Structures, vol. 28, no. 12, pp. 1691-1697, 2006.

[5] D. C. Lagoudas, Z. Bo, and M. A. Qidwai, "A unified thermodynamic constitutive model for Sma and finite element analysis of active metal matrix composites," Mechanics of Composite Materials \& Structures, vol. 3, no. 2, pp. 153-179, 1996.

[6] F. Auricchio and R. L. Taylor, "Shape-memory alloys: modelling and numerical simulations of the finite-strain superelastic behavior," Computer Methods in Applied Mechanics and Engineering, vol. 143, no. 1-2, pp. 175-194, 1997.

[7] E. Patoor, A. Eberhardt, and M. Berveiller, "Micromechanical modeling of superelasticity in shape memory alloys," Pitman Research Notes in Mathematics Series, vol. 296, pp. 38-54, 1993.

[8] F. Auricchio, S. Marfia, and E. Sacco, "Modelling of SMA materials: training and two way memory effects," Computers \& Structures, vol. 81, no. 24-25, pp. 2301-2317, 2003. 
[9] Z. C. Deng and Q. B. Li, "Deformation characteristics of shape memory alloy concrete axial component," Journal of Tsinghua University, vol. 1, 2002.

[10] W. Zhang, Experimental Study on Searing Behavior of Damaged Beams Strengthened with Prestressed Steel Strand, Xi 'an University of Technology, Xi'an, China, 2019. 